\title{
A Mobile Green Power Source for Emergency and Special Purposes Using Solar and Wind Power
}

\author{
SARA CHEN, CORINNA GONZALEZ, CRISTIAN DIAZ, \\ KENNETH LEUNG, ANTHONY LIU, NATE LOPEZ, NHAT NGUYEN, \\ ANH PHUNG, ANDREW UZUETA, KNIKOLAS WOODEN, HA THU LE \\ Department of Electrical and Computer Engineering \\ California State Polytechnic University, Pomona \\ Pomona city, California 91768 \\ UNITED STATES OF AMERICA
}

\begin{abstract}
In this project, a mobile, renewable, and versatile generation unit is designed. It utilizes solar and wind energy resources which make it usable in any location. The power source can effectively support emergency situations, such as hurricane, wildfire, earthquake, as well as special events such as remote training. It can provide at least $3.7 \mathrm{~kW}$ to run multiple tools used during search and rescue situations. Specifically, the unit has seven 5-VDC 2-A DC/USB outlets, two AC 120-V 15-A outlets, and four 6-W LED lights which serve diverse equipment and devices. Its battery system could potentially run on its own for 12 hours when supplying $1 \mathrm{~kW}$. The unit is housed in a normally-sized trailer with the total weight of around 10,000 lbs. It is very versatile as it can be towed by any popular truck to diverse locations. Simulation has shown that the unit works properly and all design expectations have been met. The use of this green power source will help save lives while keeping our air clean.
\end{abstract}

Keywords - Emergency, generation unit, mobile, power source, solar photovoltaic, wind turbine.

Received: January 8, 2021. Revised: July 20, 2021. Accepted: August 14, 2021. Published: August 26, 2021.

\section{Introduction}

As the global climate change worsens, locations around the planet experience increasing numbers of natural disasters and environmental crises [1]. In the events such as a hurricane making landfall, a wildfire getting out of control, or an earthquake happening, many people and communities are left without power while emergency services and rescue workers attempt to provide aid and restore normalcy to the affected areas [2]. This project aims to offer a valuable power supply tool to support mitigation efforts in such situations. The project not only provides a promising solution to delivering needed power to affected communities, but it does so by utilizing available renewable resources (solar and wind) in a mobile generation unit [3]. The unit is designed to be built inside a trailer that can be towed by an average-size pickup truck such as a Ford F-150. Versatility and ease of use combined with a hybrid generation method make the unit an accessible and effective method to providing needed power to communities during times of immediate climate crisis, disaster, and other special events [4] [5] . 
It has been shown that hybrid power systems that utilize both solar and wind energy result in a more efficient power output as compared to single-source renewable power systems. This is thanks to the fact that the two variable sources complement and support each other. During times where one would be producing less power the other would be producing more [6-8]. The concept of a hybrid solar and wind system is gaining a lot of attention presently and much work is being done to make it a well understood and common method of generation [9]. Because our mobile power generating unit is intended for use in all kinds of climates and weather conditions, hybrid wind-solar energy is a very suitable generation method. Additionally, the hybrid generation system would be more compact to fit on a trailer.

It is important to incorporate a Battery Energy Storage System (BESS) into the mobile generation unit to store solar and wind energy, as well as to release the energy at times of need [10-12]. A lithium-ion battery is most appropriate for this unit. The battery is efficient, lighter and more compact than lead acid batteries and it has a longer lifespan [13]. It also has a much higher energy density than other typical battery sources, such as nickel-cadmium [14].

The solar panels chosen for the mobile unit must have certain size to fit the trailer and must support the unit energy demand, as well as be cost effective [15]. The same consideration must be made when choosing the best type of wind turbine. In this case, the best option is a Vertical Axis Wind Turbine (VAWT) because it has a power output that fits power needs yet can be disassembled and placed within the trailer during transportation [16] [17].

Overall, our goal is to design a generation unit that is mobile, powerful, renewable, and versatile. Currently, there is a lot of research and development being done on power systems that utilize a hybrid of two or more energy sources. Hybrid systems using solar PV, wind turbine and battery have been investigated for different purposes, such as charging portable devices, achieving energy independence for family houses, smart farming, and other power supply purposes [18-21]. Though, our mobile hybrid power source is unique in its trailerbased design, significant power capacity, functionality and intended purposes. It provides a new option to supply power to emergency and rescue situations that increasingly arise due the climate changes. Apart from that, it can be used for other special events such as military training, camping, and public events where grid power is not available.

\section{Design of mobile power source}

The circuit diagram of the mobile generation unit is shown in Fig. 1. Its power sources include a solar PV panel, a wind turbine and a battery. A charge controller is used to charge the battery using wind or solar power. A rectifier is used to convert the $\mathrm{AC}$ power of the wind turbine to DC to charge the battery. An inverter is used to convert the battery or solar system or wind turbine DC power to AC to supply the AC loads. The unit supports seven 5-VDC 2-A DC/USB outlets, two AC 120-V 15-A outlets, and four 6-W LED lights. The unit design power output is approximately $3.7 \mathrm{~kW}$ (the total power demand of all outlets). Capacitors are used to supply reactive power (not shown in Fig. 1). A control system manages the unit operation.

Multiple factors were taken into consideration when determining the power capacity for the mobile unit. These factors included the average power consumption of single-family houses $(4-5 \mathrm{~kW})$, the size of the trailer that should be used, the number of solar panels that could fit on the trailer, and the type of wind turbine that should be used (VAWT).

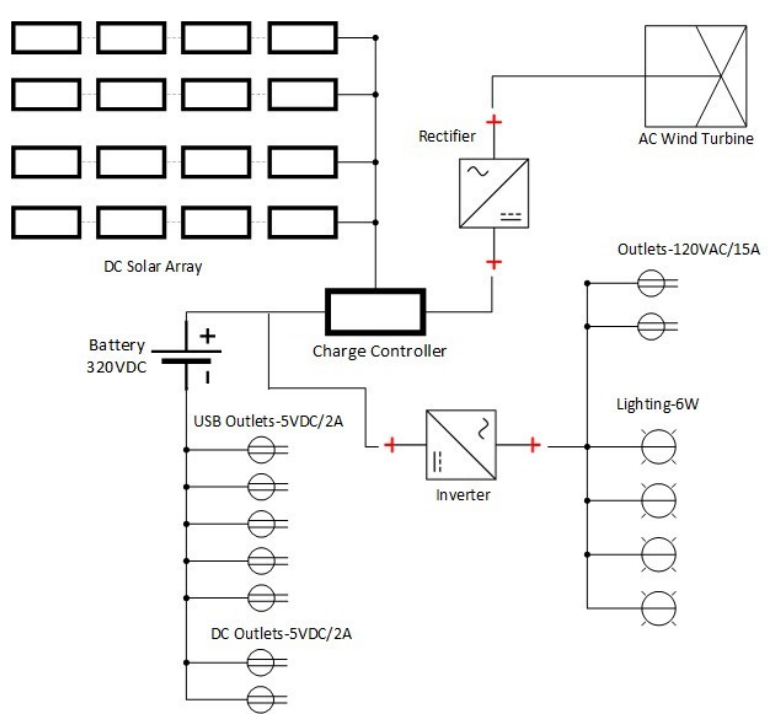

Fig. 1 Circuit diagram of mobile power source 
The power capacity of $3.7 \mathrm{~kW}$ would be sufficient to support multiple AC tools and DC/USB devices that are likely used during search and rescue situations, as well as in special events. Examples of those tools and devices are drilling tools, cutting tools, communication equipment, medical equipment, laptops, lighting etc. In case more power is needed, multiple units may be used.

The following sections present the design of individual sub-systems of the mobile generation unit. Each sub-system is implemented and tested via simulation using MATLAB Simulink. Then, the complete system is obtained by integrating the individual sub-systems and simulated for evaluating its overall performance.

\subsection{Trailer design}

The first task was determining the size, type, and shape of the trailer to house the mobile unit subsystems. After a thorough research, it was decided to use the payload capacity of popular pickup trucks in the United States (e.g. the Ford F-150) as a reference for the trailer sizing. The 2021 Ford F-150 has a towing capacity up to $12,700 \mathrm{lbs}[22,23]$. Using a towing capacity of $10,000 \mathrm{lbs}$, a relatively big trailer may be used to maximize the power capacity of the mobile source. This way, the mobile source offers great easiness of use to consumers as they can use popular trucks to move it to diverse locations. At the same time, the unit meets the desired power capacity of $3.7 \mathrm{~kW}$.

A trailer was chosen with dimensions of $8.5 \mathrm{ft} \times 27.8 \mathrm{ft} \times 7.6 \mathrm{ft}(\mathrm{W} \times \mathrm{L} \times \mathrm{H})$ that has an empty weight of 3,810 lbs and a load capacity of 6,180 lbs [24]. If filled to weight capacity, the trailer would weigh 9,990lbs which falls within the acceptable weight based on the towing capacity of $10,000 \mathrm{lbs}$. Federal legal requirements were also carefully considered in order to ensure that the unit would be legally roadworthy. The standard federal legal limits for any normally-sized trailer are $8.5 \mathrm{ft} \times 28 \mathrm{ft} \times 13 \mathrm{ft}(\mathrm{W} \times \mathrm{L} \times \mathrm{H})$. Therefore, the selected trailer is well within the legal limits.

The design features of this trailer are one of the most unique portions of this project. To make the most use of space and to capture the maximum amount of the sun irradiance, the trailer has side panels that will open up

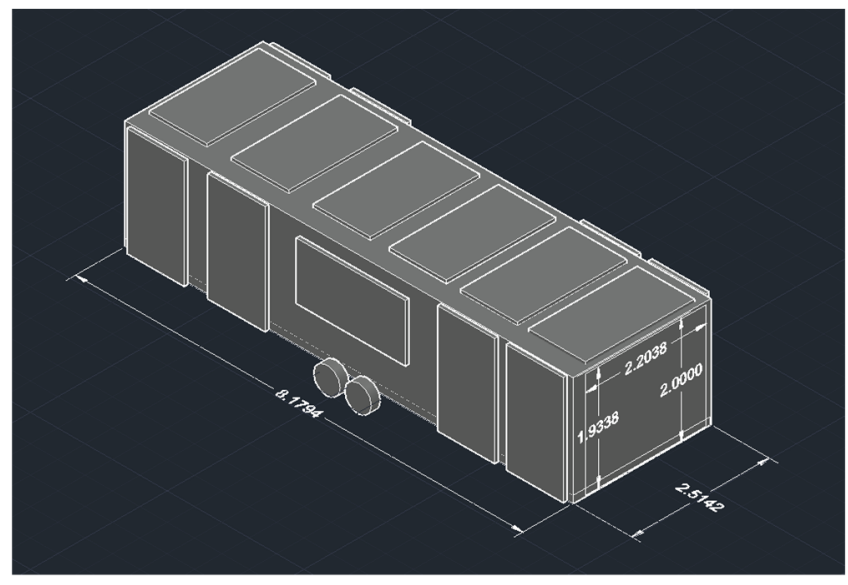

Fig. 2 Closed overhead view of trailer

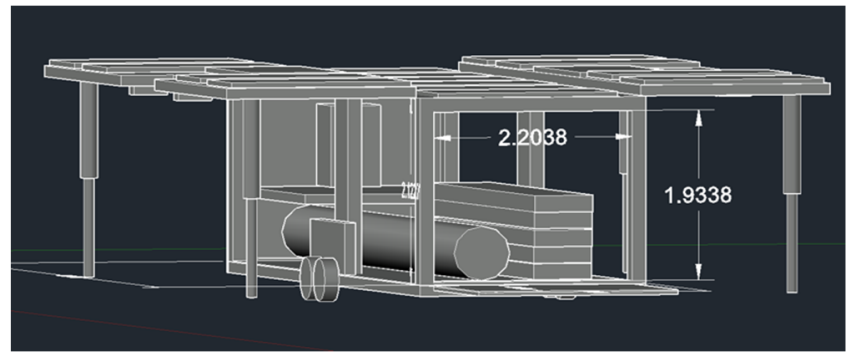

Fig. 3 Open view model of the trailer

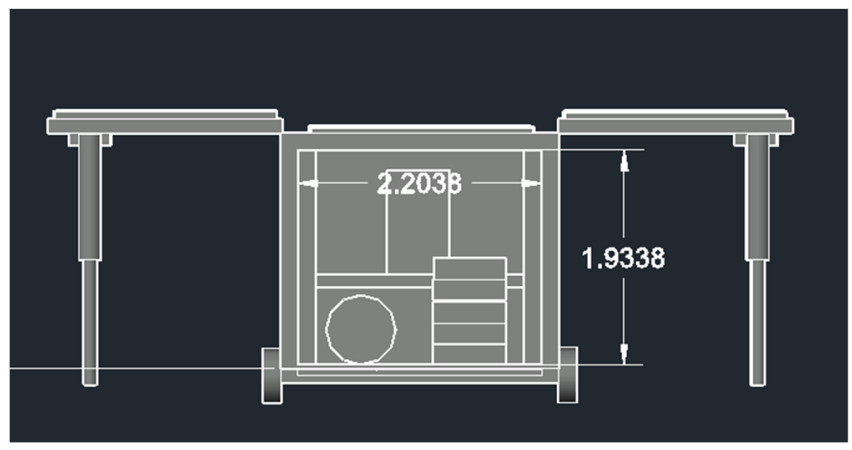

Fig. 4 Open view looking in from the back of the trailer with the wind turbine and support pole visible

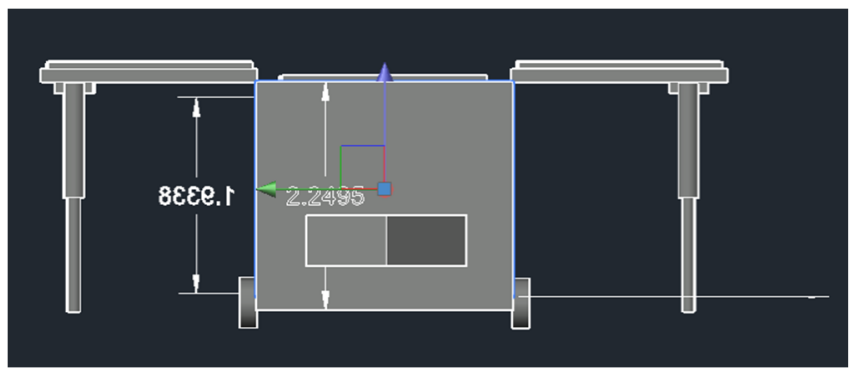

Fig. 5 Open view from the front with the battery system visible 
and out like wings. The solar panels on the lengthwise portion of the trailer will be embedded into the trailer sides. When the trailer is parked, the side panels will hinge up and out and braces on the inside of the wings will fold down for support. The 3-D trailer design is shown in Fig. 2 through Fig. 5 and in Appendix.

There are four 6-W LED lights located on the underside of the open side panels (two on each side) to provide light during evening time. The inside of the trailer contains the entire wind turbine unit that can be removed and installed next to the trailer. Everything else including the backup battery system and the rest of the components will all be housed within the trailer and firmly harnessed in place so that they will not move during transit.

\subsection{Solar PV system}

The chosen solar PV panel is E20-435-COM by SunPower ${ }^{\circledR}$ [25]. This model was chosen due to the limited number of panels that could fit on the trailer as well the highest power capacity per panel at the lowest cost. Each panel has an individual power output capacity of $435 \mathrm{~W}$ and $73.9 \mathrm{~V}$ and weighs $56 \mathrm{lbs}$. The dimensions of one panel are 81 .6in $\times 42.2$ in with a price point of about $\$ 100$ per panel and an average 25-year lifespan.

Given the solar panel dimensions and the outer dimensions of the trailer, it was calculated that 16 panels could be placed on the sides and top of the trailer, yielding a total power output capacity of $6,960 \mathrm{~W}$. The solar panel size would yield an average output of 4,230.7W (Fig. 6) which is sufficient to provide the mobile unit peak output of $3.7 \mathrm{~kW}$ during a day and some power to charge the battery. This ensures power supply in a worst-case scenario where the wind turbine does not produce power.

The solar system is implemented using a PV model of MATLAB Simulink where a 17-ohm resistor is connected between the positive and negative terminals of the PV model (Fig. 7). The irradiance input for the model can be varied at a temperature of $25^{\circ} \mathrm{C}$ (a standard test condition). An ammeter and a voltmeter are used to measure the current and voltage output of the system, as well as to calculate its power output. The

\section{Solar Model}

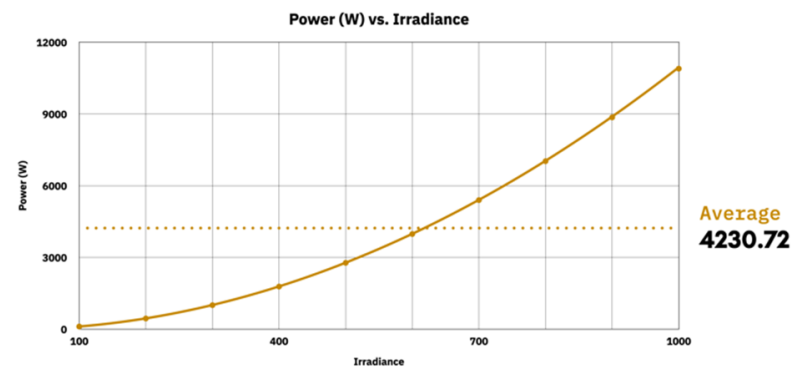

Fig. 6 Average power output of solar PV system

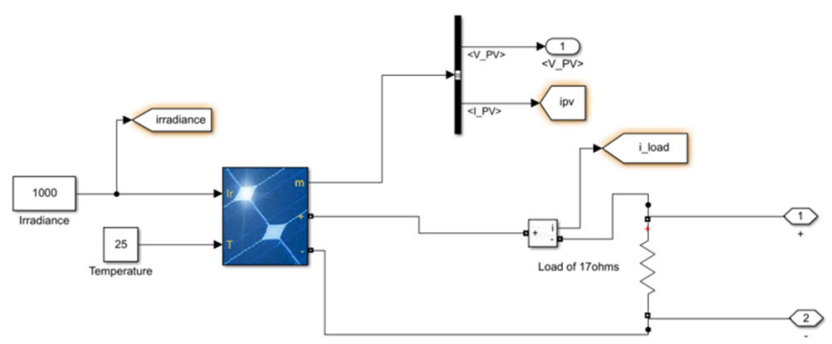

Fig. 7 Simulink model of solar PV system

solar system power output was obtained using its voltage and current outputs for different values of irradiance at a constant temperature of $25^{\circ} \mathrm{C}$. The results are shown in Fig. 6. The plot shows how increasing irradiance raises the power output of the solar system. By plotting for an average set of irradiances that could be found in any given area of the United States, the solar system average power output is estimated to be $4,230.7 \mathrm{~W}$.

\subsection{Wind turbine}

The size of the wind turbine is chosen to be $5 \mathrm{~kW}$ which would provide the mobile source peak output of $3.7 \mathrm{~kW}$ at night where the solar system does not produce power. In low-wind conditions, it can provide part of the peak demand while the remaining demand can be met by the battery. Since horizontal axis wind turbines (HAWT) take up a lot of space, a vertical axis wind turbine (VAWT) was chosen. The VAWT is more compact and is able to function on a smaller scale.

A 5-kW VAWT from Engelec Energy ${ }^{\circledR}$ was chosen for the project. This model has a power capacity of $5 \mathrm{~kW}$ and weighs $1,100 \mathrm{lbs}$ [26]. The wind turbine has a diameter of $3.6 \mathrm{~m}$ and a height of $4.5 \mathrm{~m}$. The VAWT would be elevated at least 6 meters in the air by a 
support pole. When not in use, the VAWT could be removed from the pole and stored within the trailer as shown in the trailer 3-D model.

For simulation, a time-domain model of a HAWT in [27] is used with modification to obtain the desired size of the project VAWT wind turbine. The radius of HAWT is changed to 6 meters which yields $5 \mathrm{~kW}$ at a wind speed of $10 \mathrm{~m} / \mathrm{s}$. Additionally, the power factor of the wind turbine is upgraded to 0.88 lagging by connecting capacitive components in parallel to its induction generator. The Simulink model of the wind turbine is shown in Fig. 8 where testing has shown that the model functions normally.

\subsection{Battery energy storage system}

A Fronius Solar Battery System has been chosen so that the charge capacity matches the total power output capacity of the power source [28]. This battery system has a nominal charge capacity of $12 \mathrm{kWh}$, which can store the peak power of the solar system (around $7 \mathrm{~kW}$ ) and the wind turbine $(5 \mathrm{~kW})$. Its usable capacity is 9.6 $\mathrm{kWh}$ at the depth of discharge of $20 \%$. The battery system could potentially run on its own for 12 hours when supplying $1 \mathrm{~kW}$. It has a voltage range of $320 \mathrm{~V}-$ $460 \mathrm{~V}$, a nominal charge/discharge power of $6.4 \mathrm{~kW}$, and a maximum charge/discharge current of 16A. The dimensions of the battery unit are 37.59in $\times 22.44$ in $\times$ 24.06in $(\mathrm{H} \times \mathrm{W} \times \mathrm{L})$ and its weight is $388 \mathrm{lbs}$ which can easily be installed inside the trailer.

The battery serves as a backup power sub-system to the solar-wind hybrid generation unit. A control system is used to ensure that the battery is not discharged more than $80 \%$ of its energy capacity to preserve its lifespan. The control system is described in Section 3.

For simulation, the battery block in Simulink was used to replicate the effect of a lithium-ion battery cell. Since the state of charge (SOC) has a range from $80 \%$ to $100 \%$, the nominal voltage is $300 \mathrm{~V}$, the cutoff voltage is $240 \mathrm{~V}$, and the fully charged voltage is $320 \mathrm{~V}$. The rated capacity of the battery cell is $37.5 \mathrm{Ah}$, the maximum capacity is $90 \mathrm{Ah}$, and the capacity at nominal voltage is $81.39 \mathrm{Ah}$. When being simulated, the battery model charges over time using the power from the wind turbine and the solar system to provide the fully charged voltage of $320 \mathrm{~V}$ (Fig. 10).

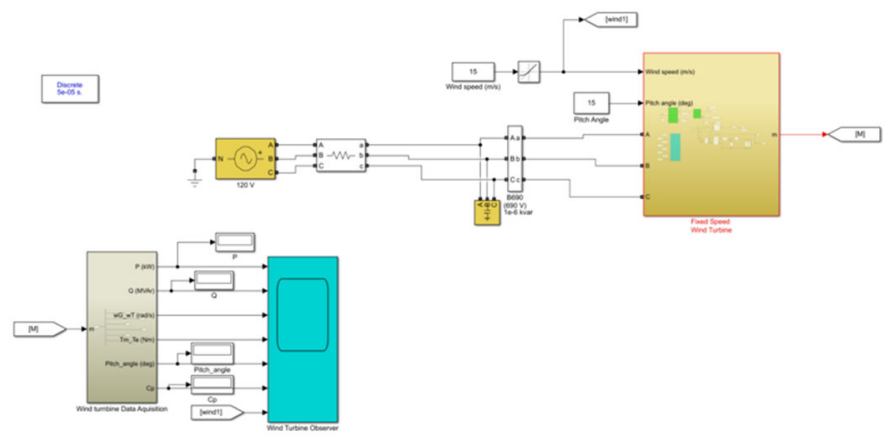

Fig. 8 Simulink model of wind turbine

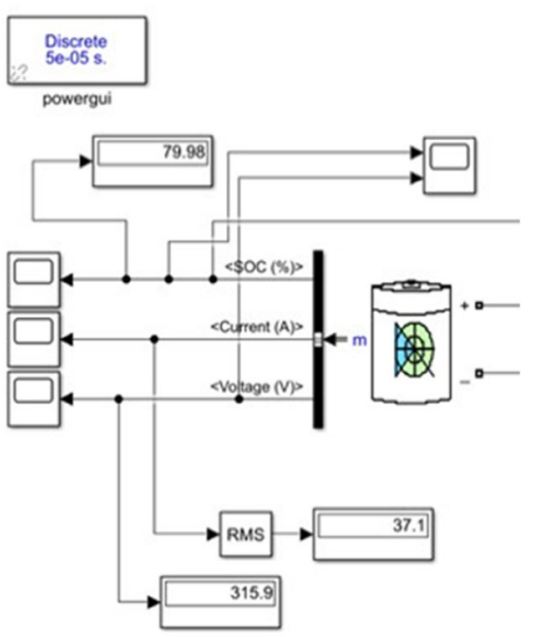

Fig. 9 Simulink model for battery system

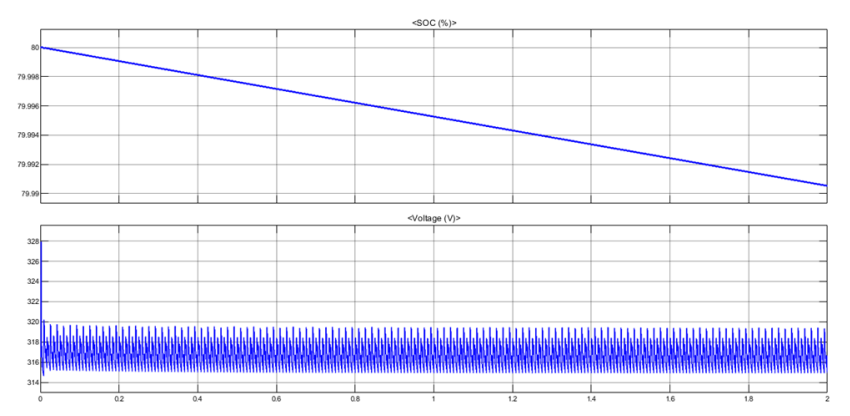

Fig. 10 State of charge behavior and voltage output of Simulink-based battery system

\subsection{AC/DC outlets and lighting}

There are four LEDs used in the mobile unit where each light is rated at $12 \mathrm{~V}, 2 \mathrm{~A}$ and $6 \mathrm{~W}$. Their power consumption is $24 \mathrm{~W}$ in total. The simulation results for the LEDs lights meet design expectation showing approximately $12.1 \mathrm{~V}$ and $2.02 \mathrm{~A}$. These results are shown in Fig. 11 and Fig. 12. 


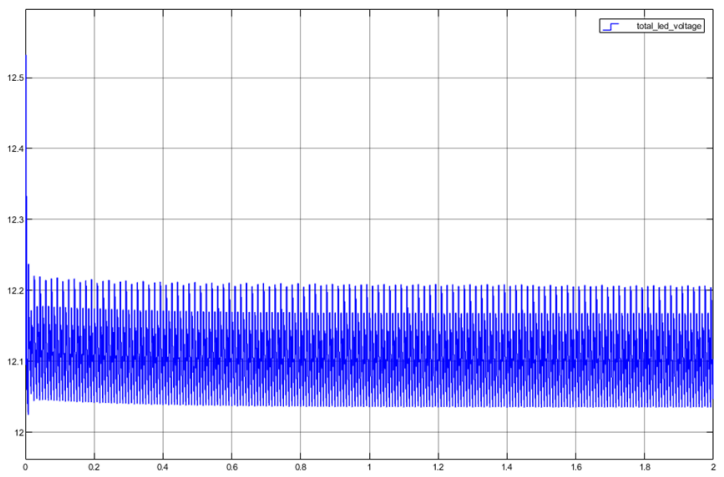

Fig. 11 Total LED voltage

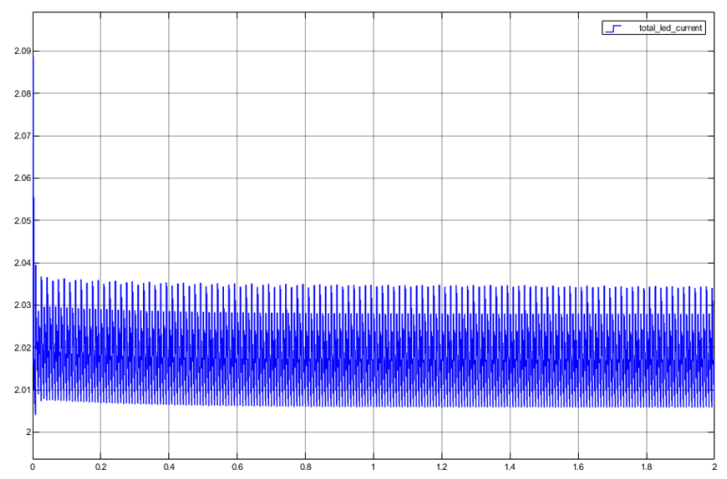

Fig. 12 Total LED current

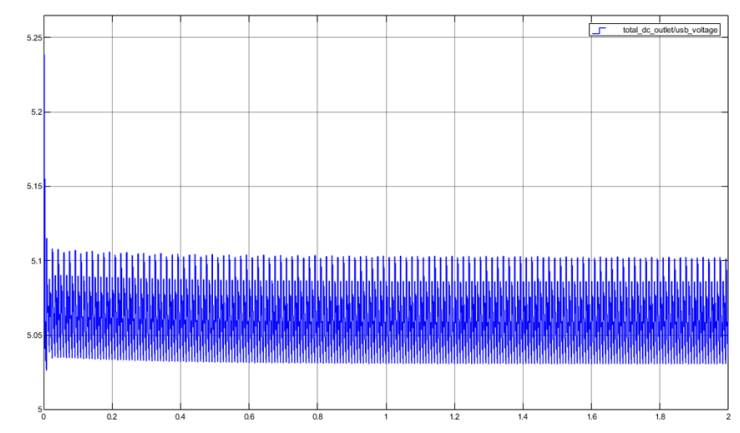

Fig. 13 Total DC and USB outlet voltage output

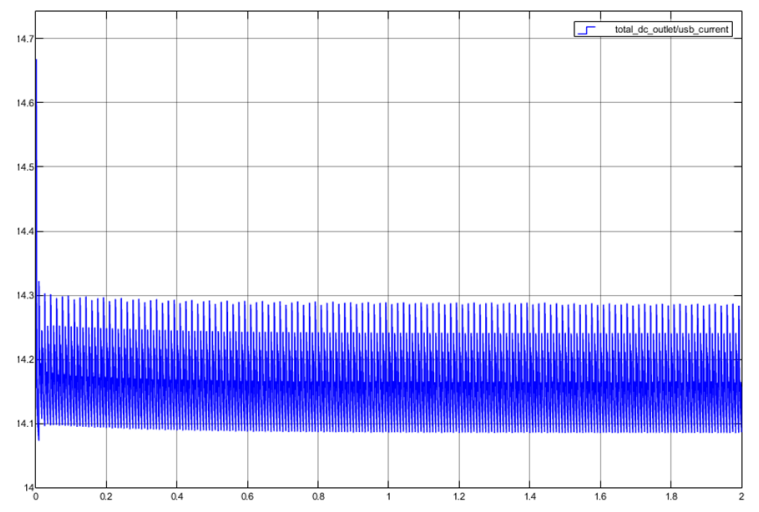

Fig. 14 Total DC and USB outlet current output
The total DC power of the two DC outlets, five USB outlets, and 4 LEDs is $95.2 \mathrm{~W}$, which meets the expected designed power of $94 \mathrm{~W}$. The results are shown in Fig. 13 and Fig. 14.

\subsection{Inverter, rectifier, and boost converter}

The inverter is used to convert the power from the solar system, wind turbine, or the battery to AC power to supply AC loads. It is rated based on the solar system capacity, aiming to convert most of the solar power. Recall from Section 2.2 that the maximum capacity of the solar system is $6,960 \mathrm{~W}$ and the average power output is $4,230.7 \mathrm{~W}$. Based on these outputs, a commercial 6-kW inverter has been chosen where the size is around the average of $6,960 \mathrm{~W}$ and $4,230.7 \mathrm{~W}$ $(1 / 2 \times(6960+4230.7)=5595 \mathrm{~W})$. The device weighs $148 \mathrm{lbs}$ and has physical dimensions of 9.53in $\times$ 18.39in $\times 24.09$ in $(\mathrm{H} \times \mathrm{W} \times \mathrm{L})$. Its input voltage is $48 \mathrm{VDC}$ and its output voltage is 120VAC [29].

At 90-percent efficiency, the inverter AC output is $5400 \mathrm{~W}$ while the designed peak output of the mobile unit is $3.7 \mathrm{~kW}$. This offers a possibility to add one more $\mathrm{AC}$ outlet to the mobile unit if desired.

In the system simulation, the inverter must provide $120-\mathrm{V}, 60-\mathrm{Hz}$ AC output while taking power from the battery. This is achieved by using two logic switches and two inductors inside the inverter to control the output current as the battery SOC varies. A series of switches are also added at the output of the inverter to regulate the power drawn from the battery by turning on and off one or both AC outlets. This is done based on the amount of energy remained in the battery to protect it from permanent damage. The inverter logic switches and the inductors are shown in Fig. 15, along with the AC outlets.

For the wind turbine, a rectifier is used to converts its 3-phase AC voltage to DC voltage. In addition, a DCDC boost converter is connected in series with the rectifier to raise the voltage to a value that is adequate to charge the battery.

The Simulink-based model of the rectifier and the DC-DC boost converter for the wind turbine is shown in Fig. 16. The DC-DC boost converter uses a diode, a MOSFET, an inductor, and a capacitor. 


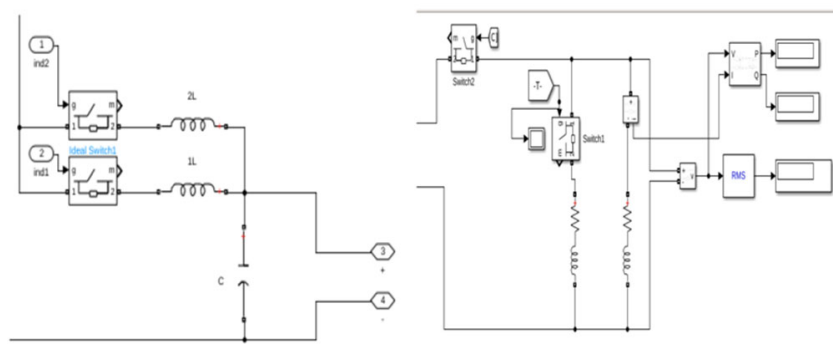

Fig. 15 Inverter switches and inductors (left) and $\mathrm{AC}$ outlets (right)

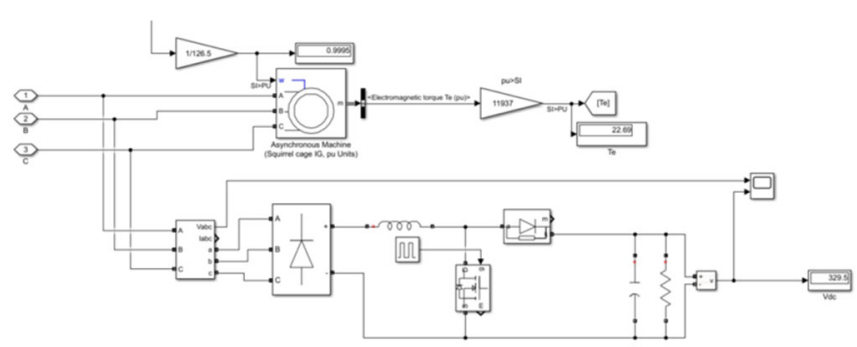

Fig. 16 Simulink model of rectifier circuit with DC-DC boost converter for wind turbine

\section{Control system}

The control system manages the outlet operation and protects the battery by monitoring its state of charge. The control logic is shown in Fig. 17 and the control scheme works as follows.

Sensors read power coming into the battery (i.e. the power output from the solar system and the wind turbine) and battery state of charge (SOC). If the battery SOC is less than or equal $40 \%$ the control system will display "Low battery" alert. If the battery SOC is less than $30 \%$ it will open circuit breakers to disconnect all outlets. The lower threshold for the battery SOC (i.e. the depth of discharge) may be reset to $20 \%$. This is to preserve the battery lifespan.

The control system also monitors the power input to the battery and switches the AC outlets based on available power. Recall that the designed peak power consumption of an AC outlet is $1800 \mathrm{~W}(120 \mathrm{~V}$ and $15 \mathrm{~A})$ so the two AC outlets consume $3600 \mathrm{~W}$ in total. If the power input to the battery is less than $3600 \mathrm{~W}$, the control system will open a circuit breaker to disconnect AC outlet \#2 while letting AC outlet \#1 operate. In case
Sara Chen, Corinna Gonzalez, Cristian Diaz, Kenneth Leung, Anthony Liu, Nate Lopez, Nhat Nguyen, Anh Phung, Andrew Uzueta, Knikolas Wooden, Ha Thu Le

the power input to the battery is less than $1800 \mathrm{~W}$, the control system will disconnect both AC outlets.

When one of the AC outlets is switched off, an excessive current would be routed to the other $\mathrm{AC}$ outlet. This is fixed by switching between two different inductors placed inside the inverter. As mentioned in Section 2.6, two logic switches and two inductors are used inside the inverter to control its output current as the battery SOC varies. A series of switches are also added at the output of the inverter to regulate the power drawn from the battery by turning on and off one or both AC outlets.

Note that the peak power output of the AC outlet can be increased by raising the designed current limit of 15A. This will increase the power output of the mobile unit to a higher value than the designed value of $3.7 \mathrm{~kW}$.

A charge controller (shown in Fig. 1) is part of the control system. It helps monitor power flow, battery charging, and activate the emergency shut off if needed. Further explanation of the control scheme is provided in the pseudocode below.

\section{Pseudocode for control system logic in Fig. 17}

START. Turn on the battery control system and sensors will read power coming into the battery and battery state of charge (SOC).

If $\mathrm{SOC}$ is less than or equal to $40 \%$ display "Low Battery" alert. If SOC is less than $30 \%$ open circuit breakers to disconnect all outlets.

If the previous check is false, close circuit breakers to connect load to DC outlets.

If power input to battery is less than $1800 \mathrm{~W}$ open circuit breakers to disconnect load from AC outlets \#1 and $\# 2$.

If the previous check is false, close circuit breaker to connect load to AC outlet \#1.

If power input to battery is less than $3600 \mathrm{~W}$ keep circuit breakers open to disconnect load from AC outlet \#2.

If the previous check is false, close circuit breaker to connect load to AC outlet \#2.

START. Readings will continue until the battery control system is shut off. 


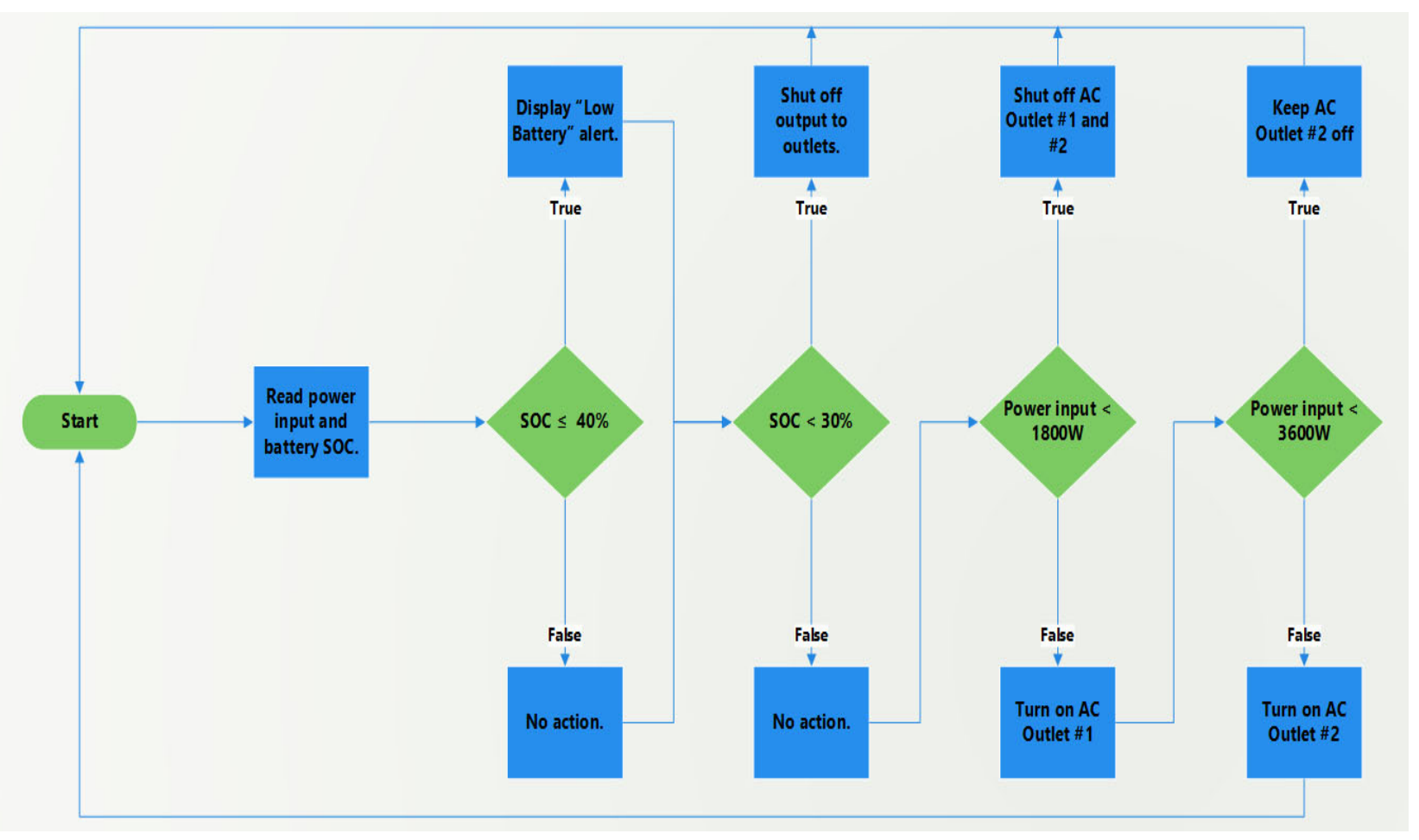

Fig. 17 Flowchart for control system logic

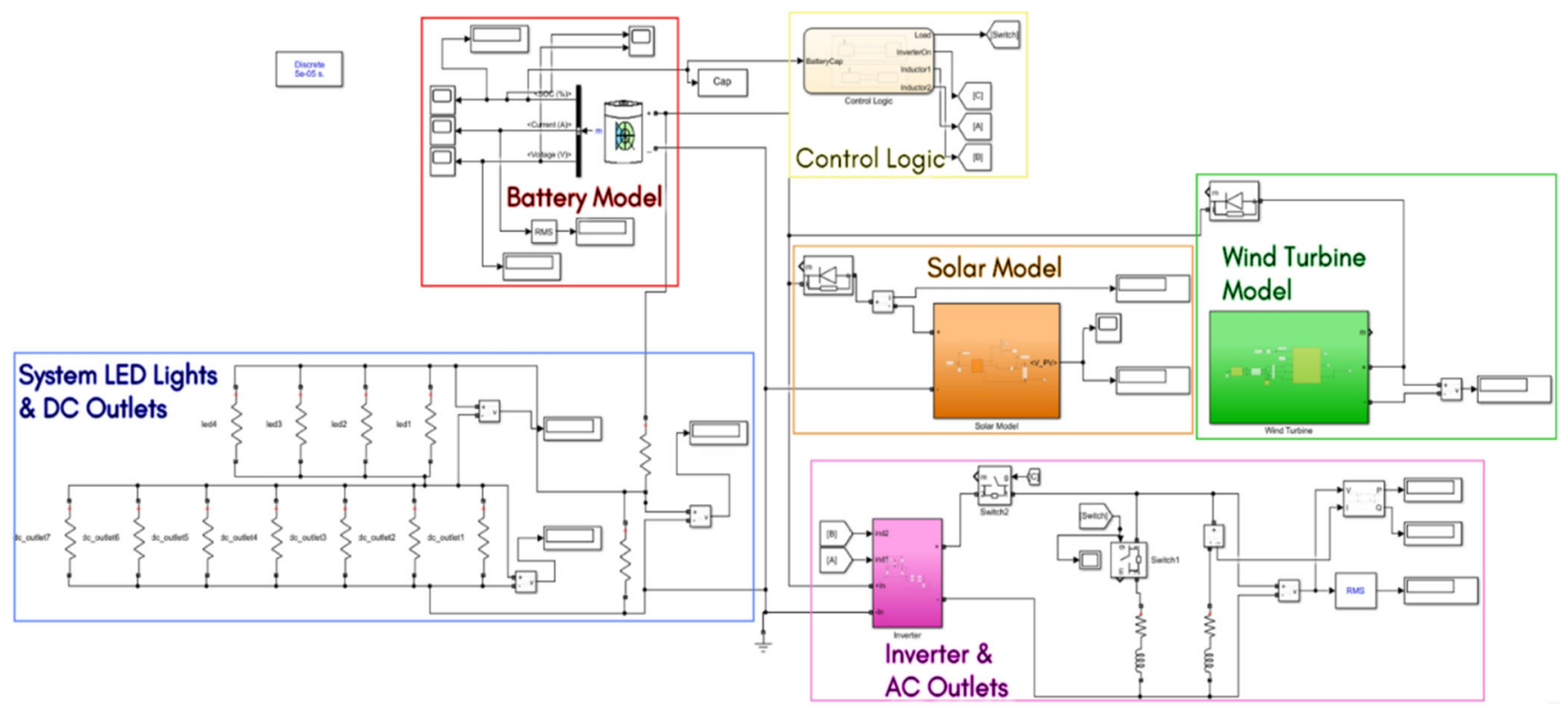

Fig. 18 Simulink-based complete mobile power generation unit 


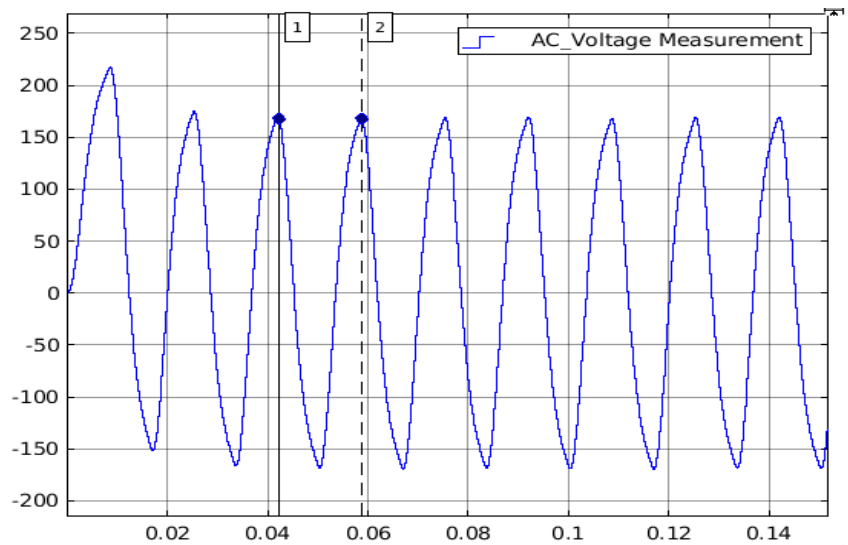

Fig. 19 Sinusoidal voltage measurement for AC outlets: $120.8 \mathrm{~V}$ RMS, $386.8 \mathrm{~V}$ peak-to-peak, $60.566 \mathrm{~Hz}$

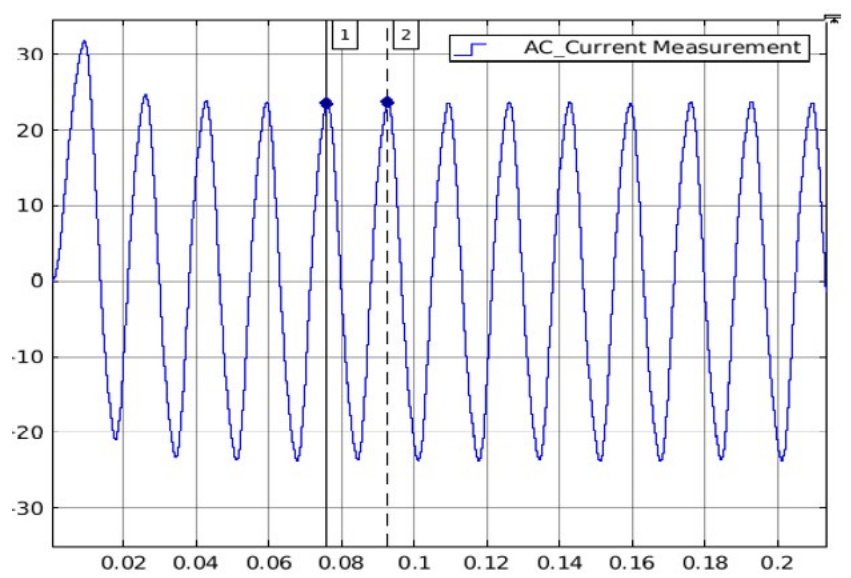

Fig. 20 Sinusoidal current measurement for AC outlets: 16.69A RMS, 55.61A peak-to-peak, $59.63 \mathrm{~Hz}$

\section{Simulation result of complete mobile power generation unit}

After testing all sus-systems to ensure that they function normally, they are integrated into the mobile power source, whose Simulink modelling is shown in Fig. 18. The complete generation unit is simulated to measure its overall performance.

Simulation results of the AC outlets are shown in Fig. 19 and Fig. 20. As seen from the results, the outlet sinusoidal voltage measurement is $120.8 \mathrm{~V}$ RMS at a frequency of $60.566 \mathrm{~Hz}$. The sinusoidal current measurement is $16.69 \mathrm{~A}$ RMS at a frequency of
$59.634 \mathrm{~Hz}$. The results show that the AC outlets work properly and meet the design expectations of $120 \mathrm{~V}$ and $15 \mathrm{~A}$ for voltage and current outputs.

Various simulations also show that the control system and the DC/USB outlets work as expected.

\section{Conclusion}

In this project, a mobile, renewable, and versatile generation unit is designed. It utilizes solar and wind energy resources which make it usable in any location. The power source can be used in emergency situations, such as hurricane, wildfire, earthquake, as well as special events such as remote training.

The generation unit can provide at least $3.7 \mathrm{~kW}$ to run multiple tools used during search and rescue situations. Specifically, it has seven 5-VDC 2-A DC/USB outlets, two AC 120-V 15-A outlets, and four 6-W LED lights which serve diverse equipment and devices. When the solar system and the wind turbine produce power at the same time, the unit can provide up to $5.4 \mathrm{~kW}$ without the battery.

The battery system could potentially run on its own for 12 hours when supplying $1 \mathrm{~kW}$. The unit is placed on a normally-sized trailer with the total weight of around 10,000 lbs. It is very versatile as it can be towed by any popular truck to diverse locations. This gives its users great easiness and flexibility.

Multiple simulations have shown that the unit works properly and all design expectations have been met. The AC outlets provide a near perfect sinusoidal waveform of around $60-\mathrm{Hz}$ frequency and designed voltage and current values close to $120 \mathrm{~V}$ and $15 \mathrm{~A}$.

The COVID-19 pandemic social distancing and other requirements have prevented the research team from building a prototype of the power source so this is left as a future work. We also would like to improve the control system to manage the operation of the mobile unit more effectively. The use of this green power source will help save lives while keeping our air clean. 
Sara Chen, Corinna Gonzalez, Cristian Diaz, Kenneth Leung, Anthony Liu, Nate Lopez, Nhat Nguyen, Anh Phung, Andrew Uzueta, Knikolas Wooden, Ha Thu Le

\section{Appendix}

The following figures are additional images of the 3-D design of the trailer described in Section 2.1.

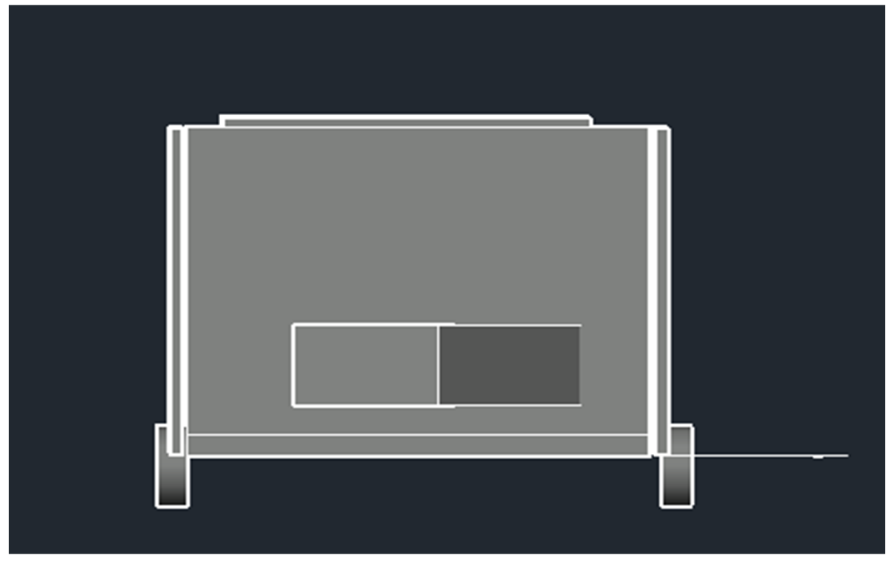

Fig. 21 Closed view from rear of trailer

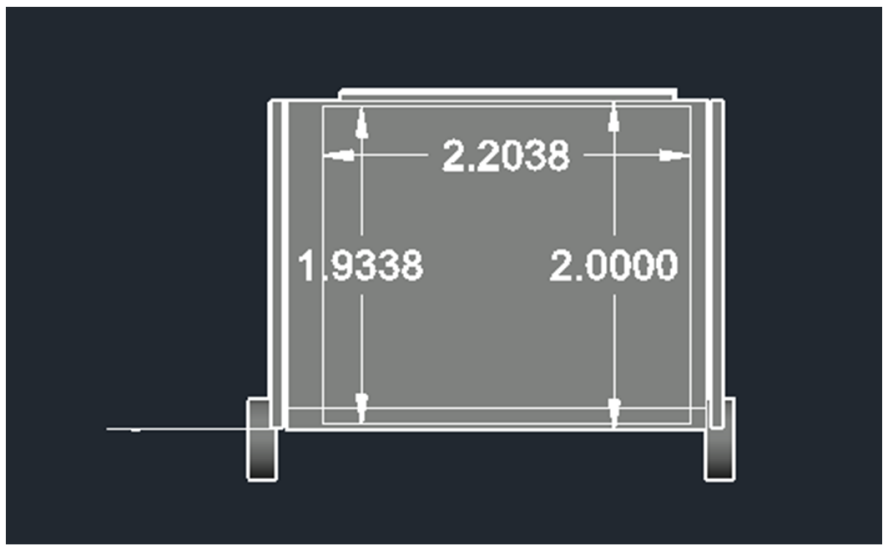

Fig. 22 Closed view of trailer showing dimensions from rear

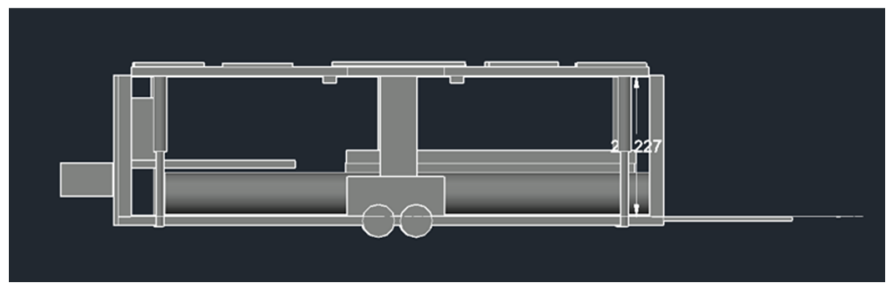

Fig. 23 Open view from side of trailer

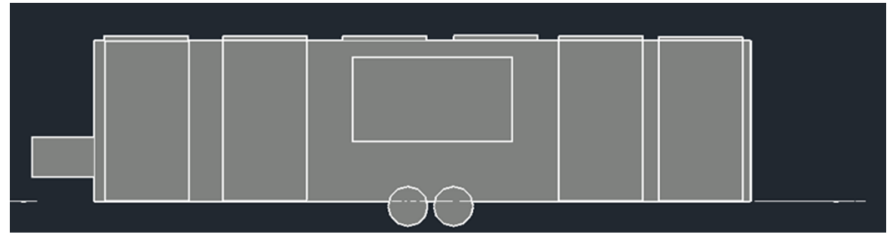

Fig. 24 Closed view from side of trailer

\section{References}

[1] M. Bates, "Natural Disasters and Public Health," IEEE Pulse, vol. 10, no. 2, pp. 24-27, 2019, doi: 10.1109/MPULS.2019.2899704.

[2] A. Ariani, J. Lewis, and P. K. Ray, "The vulnerability assessment for emergency response plans," in 2016 IEEE International Symposium on Technology and Society (ISTAS), 20-22 Oct. 2016 2016, pp. 1-4, doi: 10.1109/ISTAS.2016.7764041.

[3] S. Jeong, H. Kang, and Y. An, "An enhanced spider web chart method for climate change risk quantification in electrical facilities," in 2017 International Conference on Information and Communication Technology Convergence (ICTC), 18-20 Oct. 2017 2017, pp. 76-80, doi: 10.1109/ICTC.2017.8190946.

S. Jeong and Y. An, "Climate change risk assessment method for electrical facility," in 2016 International Conference on Information and Communication Technology Convergence (ICTC), 19-21 Oct. 2016 2016, pp. 184-188, doi: 10.1109/ICTC.2016.7763464.

ElectricChoice.com. "How Much Electricity On Average Do Homes In Your State Use? (Ranked by State)." https://www.electricchoice.com/blog/electricit y-on-average-do-homes/ (accessed 2020).

P. S. Pai and S. Beevi, "Dual maximization of solar power for medium power application," in 2013 International Conference on Renewable Energy Research and Applications (ICRERA), 20-23 Oct. 2013 2013, pp. 269-273, doi: 10.1109/ICRERA.2013.6749764.

Z. Wang et al., "Research on the active power coordination control system for wind/photovoltaic/energy storage," in 2017 IEEE Conference on Energy Internet and Energy System Integration (EI2), 26-28 Nov. 2017 2017, pp. 1-5, doi: 10.1109/EI2.2017.8245403.

[8] N. P. Kumar, K. Balaraman, and C. S. R. Atla, "Optimizing system elements for hybrid wind 
- solar PV power plant," in 2016 Biennial International Conference on Power and Energy Systems: Towards Sustainable Energy (PESTSE), 21-23 Jan. 2016 2016, pp. 1-6, doi: 10.1109/PESTSE.2016.7516421.

L. G. Vasant and V. R. Pawar, "Optimization of solar-wind energy system power for battery charging using MPPT," in 2017 International Conference on Energy, Communication, Data Analytics and Soft Computing (ICECDS), 1-2 Aug. 2017 2017, pp. 1308-1310, doi: 10.1109/ICECDS.2017.8389656.

[10] G. Barchi, G. Miori, D. Moser, and S. Papantoniou, "A Small-Scale Prototype for the Optimization of PV Generation and Battery Storage through the Use of a Building Energy Management System," in 2018 IEEE International Conference on Environment and Electrical Engineering and 2018 IEEE Industrial and Commercial Power Systems Europe (EEEIC / I\&CPS Europe), 12-15 June 2018 2018, pp. 1-5, doi: 10.1109/EEEIC.2018.8494012.

[11] M. Mao, J. Su, C. Liuchen, G. Zhang, and Y. Zhou, "Controller for $1 \mathrm{~kW}-5 \mathrm{~kW}$ wind-solar hybrid generation systems," in 2008 Canadian Conference on Electrical and Computer Engineering, 4-7 May 2008 2008, pp. 001175 001178, doi: 10.1109/CCECE.2008.4564723.

[12] A. Saipet and S. Nuchprayoon, "On Controlling Power Ramping and Output of Grid-Connected Rooftop Solar PV Using Battery Energy Storage System," in 2019 IEEE International Conference on Environment and Electrical Engineering and 2019 IEEE Industrial and Commercial Power Systems Europe (EEEIC / I\&CPS Europe), 11-14 June 2019 2019, pp. 1-5, doi: 10.1109/EEEIC.2019.8783980.

[13] EnergySage.com. "How To Choose The Best Battery For A Solar Energy System." https://www.energysage.com/solar/solarenergy-storage/what-are-the-best-batteriesfor-solar-panels/ (accessed 2020).
[14] batteryuniversity.com. "Is Lithium-Ion The Ideal Battery?" https://batteryuniversity.com/learn/archive/is lithium_ion_the_ideal_battery_ (accessed 2020).

[15] V. A. Banoni, A. Arnone, M. Fondeur, A. Hodge, J. P. Offner, and J. K. Phillips, "The place of solar power: an economic analysis of concentrated and distributed solar power," (in eng), Chem Cent J, vol. 6 Suppl 1, no. Suppl 1, pp. S6-S6, 2012, doi: 10.1186/1752-153X-6S1-S6.

[16] J. Fadil, Soedibyo, and M. Ashari, "Performance analysis of vertical axis wind turbine with variable swept area," in 2017 International Seminar on Intelligent Technology and Its Applications (ISITIA), 2829 Aug. 2017 2017, pp. 217-221, doi: 10.1109/ISITIA.2017.8124083.

[17] J. Fadil, Soedibyo, and M. Ashari, "Performance comparison of vertical axis and horizontal axis wind turbines to get optimum power output," in 2017 15th International Conference on Quality in Research (QiR) : International Symposium on Electrical and Computer Engineering, 24-27 July 2017 2017, pp. 429-433, doi: 10.1109/QIR.2017.8168524.

[18] H. Cao, J. Gonzalez, N. Dimetry, J. Cate, R. Huynh, Ha Thu Le, "A Solar-Based Versatile Charging Station for Consumer AC-DC Portable Devices," International Journal of Power Systems, vol. 4, pp. 115-131, 2019.

[19] B. Postovoit, D. Susoeff, D. Daghbas, J. Holt, C. P. Pomona, and Ha Thu Le, "A Solar-Based Stand-Alone Family House for Energy Independence and Efficiency," in 2020 IEEE Conference on Technologies for Sustainability (SusTech), 2020, pp. 1-6, doi: 10.1109/SusTech47890.2020.9150500.

[20] J. Calderon, J. Cureg, M. Diaz, J. Guzman, C. Rudd, and Ha Thu Le, "Smart Agriculture: An Off-Grid Renewable Energy System for Farms using Wind Power and Energy Storage," in 2019 IEEE Power \& Energy Society Innovative Smart Grid Technologies 
Conference (ISGT), 18-21 Feb. 2019 2019, pp. 1-5, doi: 10.1109/ISGT.2019.8791576.

[21] Anh-Huy Le, A. Giourdjian, A. Frankyan, V. Mandany, and Ha Thu Le, "Design, sizing and operation of a hybrid renewable energy system for farming," in 2016 IEEE Power \& Energy Society Innovative Smart Grid Technologies Conference (ISGT), 2016, pp. 1-5, doi: 10.1109/ISGT.2016.7781209.

[22] C. Wardlaw. "10 Most Popular Trucks." https://www.jdpower.com/cars/trucks/10most-popular-trucks (accessed December 1, 2020).

[23] "F-150 IS UP FOR THE JOB." Ford Motor Company.

https://www.ford.com/trucks/f150/features/po wer/?gclid=EAIaIQobChMI_MWGnZHV8QI V9T6tBh37Rg9aEAAYASAAEgJoWfD_Bw E\&searchid $=757864977|39397447585| 99442$ 2946262|\&ef_id=EAIaIQobChMI_MWGnZH V8QIV9T6tBh37Rg9aEAAYASAAEgJoWfD BwE:G:s\&s kwcid=AL!2519!3!244250334 719!e!!g!!2021\%20ford\%20f\%20150\%20dies el\%20towing\%20 capacity\&gclsrc=aw.ds (accessed 2021).

[24] T. Superstore. "Cargo Pro 8.5 x 28 Enclosed Car Trailer." https://www.trailersuperstore.com/shop/cargopro-8-5-x-28-enclosed-car-trailer-stealthpackage/ (accessed.

SunPower.com. "SunPower E-Series Commercial Solar Panels | E20-435-COM." https://us.sunpower.com/sites/default/files/me dia-library/data-sheets/sunpower-e-seriescommercial-solar-panels-e20-435-comdatasheet-521912-revb_1.pdf (accessed Novembr 1, 2020).
Engelec Energy. "EN-5kW-H Vertical Axis Wind Turbine Generator VAWT." http://www.engelecenergy.com/vertical-axiswind-turbine-generator-en-5kw-h-vawt.html (accessed November 1, 2020).

[27] S. Santoso and Ha Thu Le, "Fundamental timedomain wind turbine models for wind power studies," Elsevier Renewable Energy vol. 32, no. 14, pp. 2436-2452, 2007, doi: 10.1016/j.renere.2006.12.008.

Z. H. Bills. "Fronius Solar Battery System $12 \mathrm{~kW} . "$

https://www.zerohomebills.com/product/froni us-solar-battery-system-

12kw/\#: :text=Fronius\%20Solar\%20Battery $\% 20$ System $\% 2012 \mathrm{~kW} \% 20$ is $\% 20 \mathrm{a} \% 20 \mathrm{high} \%$ 2Dperformance $\% 20$ Lithium, temporarily $\% 20$ s tored $\% 20 \mathrm{in} \% 20 \mathrm{a} \% 20$ battery (accessed November 1, 2020).

[29] Unbound Solar. "SMA Sunny Island 6048-US$10 \quad 6,000 \mathrm{~W} \quad 48 \mathrm{~V} \quad$ Inverter." https://unboundsolar.com/2945484/sma/solarinverters-electrical/sma-sunny-island-6048us-10-6-000w-48v-inverter (accessed November 1, 2020).

Contribution of Individual Authors to the Creation of a Scientific Article (Ghostwriting Policy)

The authors equally contributed in the present research, at all stages from the formulation of the problem to the final findings and solution.

Sources of Funding for Research Presented in a Scientific Article or Scientific Article Itself

No funding was received for conducting this study.

\section{Conflict of Interest}

The authors have no conflicts of interest to declare that are relevant to the content of this article.

Creative Commons Attribution License 4.0 (Attribution 4.0 International, CC BY 4.0)

This article is published under the terms of the Creative Commons Attribution License 4.0 https://creativecommons.org/licenses/by/4.0/deed.en 